\title{
The diversity of the Polytrichopsida—a review
}

\author{
NEIL BELL ${ }^{1}$, ISURU KARIYAWASAM ${ }^{1,2}$, JORGE FLORES ${ }^{3}$ \& JAAKKO HYVÖNEN J $^{3,4}$ \\ ${ }^{1}$ Royal Botanic Garden Edinburgh, 20A Inverleith Row, Edinburgh, EH3 5LR, Scotland \\ "=nbell@rbge.org.uk; (1) https://orcid.org/0000-0002-2401-2968 \\ ${ }^{2}$ Department of Botany, Faculty of Applied Sciences, University of Sri Jayewardenepura, Gangodawila, Nugegoda, Sri Lanka \\ ఏ"isurufasi@gmail.com; @ https://orcid.org/0000-0002-2527-3502 \\ ${ }^{3}$ Finnish Museum of Natural History (Botany), PO Box 7, 00014 Univ. Helsinki, Finland \\ झ"jorge.flores@helsinki.fi; ○ https://orcid.org/0000-0002-2657-6126 \\ ${ }^{4}$ Organismal \& Evol. Biology \& Viikki Plant Sci. Center, Univ. Helsinki, Finland

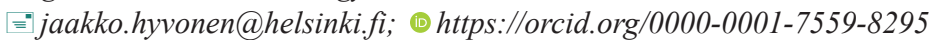

\begin{abstract}
The class Polytrichopsida are a phylogenetically isolated moss lineage of around 200 species. The nematodontous peristome found in most species has a fundamentally different structure from the arthrodontous peristome of the Bryopsida and may be independently evolved from an ancestral type of spore dehiscence apparatus. Within the class generic circumscriptions and relationships are now fairly confidently resolved and more or less congruent with the most developed pre-molecular taxonomy. Drawing on previously published datasets, we conducted a phylogenetic analysis of a novel matrix of terminals representing diversity across the Polytrichopsida. The class comprises 17 extant genera and two known only from fossils. Most of these are numerically small, the most notable exception being Pogonatum with over 50 species. Considering current phylogenetic hypotheses in the light of morphology and global distributions, Alophosia, Bartramiopsis and Lyellia, the earliest diverging lineages according to recent phylogenetic analyses, appear to be relicts, with scattered and disjunct distributions. All of these genera lack peristomes, while all later originating lineages have nematodontous peristomes developed from bundles of "u-shaped" whole cells. The genus Dawsonia, sister to all other peristomate taxa, differs in its unique peristome composed of long, bristle-like teeth arranged in concentric layers. Many members of some traditional genera found to be polyphyletic in recent studies are part of a southern hemisphere grade and only distantly related to the superficially similar northern hemisphere species with which they were historically classified. A large apical clade including eight genera accounts for the majority of the diversity, these being most speciose in northern temperate regions or the Asian tropics. Many of the Polytrichopsida are relatively large plants with well-developed vasculature and a "pseudo-mesophyll" capable of supporting relatively high rates of photosynthesis in moist, well-illuminated environments. With ten described species, Cenozoic fossils of Polytrichopsida are fairly numerous compared with other mosses. Records of fossils from older sediments have been rare, but recently several well-preserved fossils of Polytrichopsida have been found, most of which still await detailed description.
\end{abstract}

Keywords: bryophytes, cladistics, fossils, mosses, nomenclature, phylogeny, systematics, taxonomy

\section{Introduction}

The class Polytrichopsida, informally referred to as the "hair-cap mosses", are a phylogenetically isolated lineage of around 200 species occurring outside of the Bryopsida, the major clade in which the vast majority of extant moss diversity is found. The only other similarly speciose non-bryopsidan class is the Sphagnopsida, although the Polytrichopsida have considerably greater generic, macromorphological, and extant phylogenetic diversity (e.g. Bell et al. 2010a; Huttunen et al. 2018; Smith 1971). Most species are peristomate, although the nematodontous peristome found in the Polytrichopsida (Figs. 1,2) is entirely different in structure to the arthrodontous peristome of the Bryopsida and may be independently evolved from an ancestral type of spore dehiscence apparatus lacking teeth or processes entirely (Bell \& Hyvönen 2008; Bell \& Hyvönen 2010a; Bell et al. 2015; Liu et al. 2019). Alternatively, if the Polytrichodopsida form a clade with the Tetraphidopsida (e.g. Liu et al. 2019), these groups could have shared a common ancestor with a plesiomorphic form of toothed nematodontous peristome. Current phylogenetic hypotheses based on the most extensive molecular character sampling available agree that the Oedipodiopsida, Tetraphidopsida, Polytrichopsida and Bryopsida are a clade, but conflict on whether the first three form a grade or a monophyletic group sister to the Bryopsida (Liu et al. 2019). 

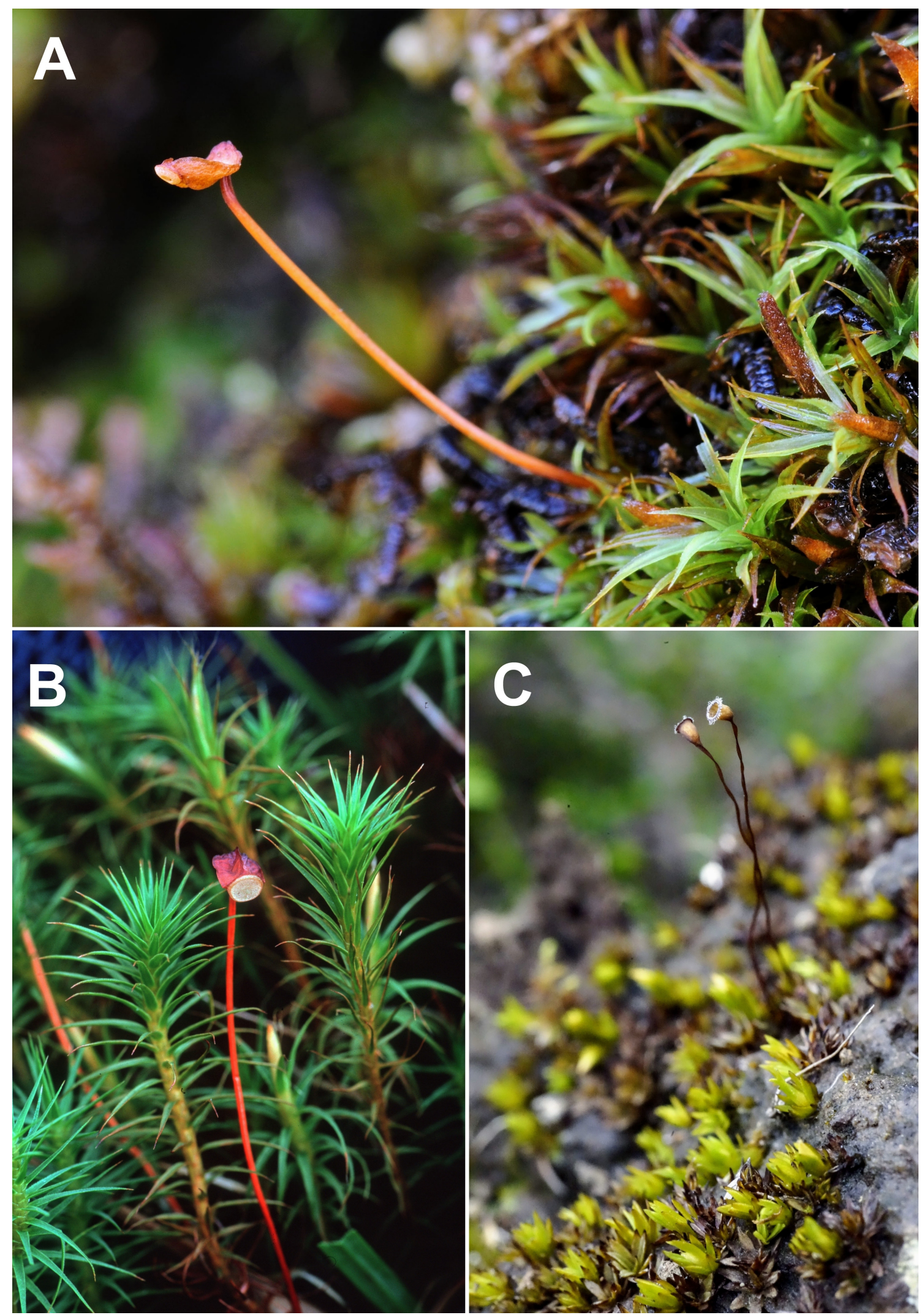

FIGURE 1. Representatives of the Polytrichopsida showing overall morphology of selected genera. (A). Alophosia azorica, lacking a peristome but with a flattened disc at the capsule mouth surrounding a small aperture, sealed by a "stopper" (formed from the apical section of the columella) prior to dehiscence. The leaves entirely lack lamellae. (B). Polytrichum commune, with 64 peristome teeth surrounding a large, drum-like epiphragm and ventral leaf surfaces almost entirely covered with tightly appressed lamellae. (C). Pogonatum nanum, with very wide-mouthed capsules and robust peristome teeth (the epiphragms have been lost in these mature sporophytes). The gametophytes of this plant have persistent protonema from which many short gametophores are produced. 

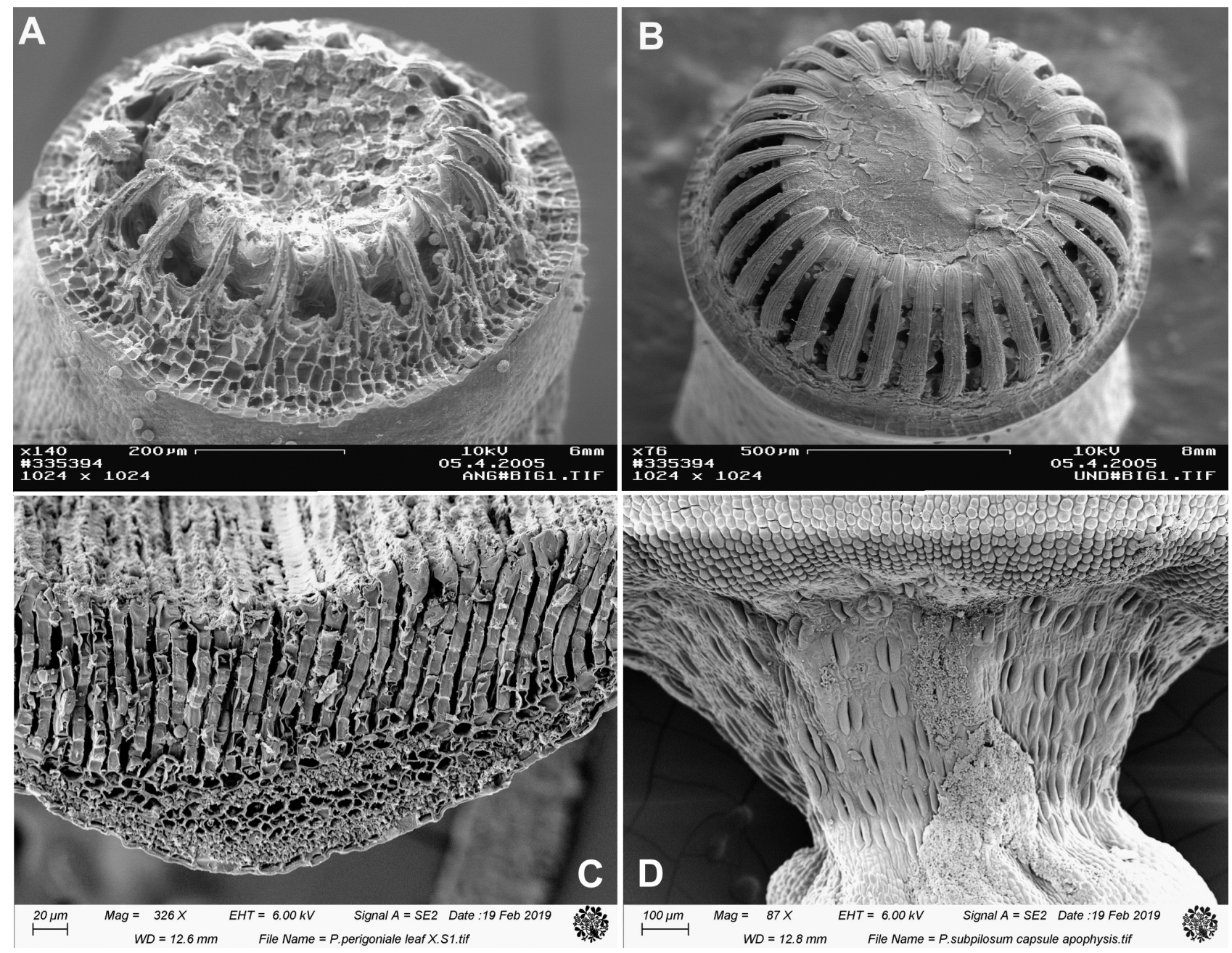

FIGURE 2. SEM micrographs of Polytrichaceae. (A) Notoligotrichum angulatum, peristome and epiphragm. (B) Atrichum undulatum, peristome and epiphragm. (C) Cross section of the leaf of Polytrichum perigoniale showing lamellae. (D) Apophysis (swollen basal part of the capsule) of Polytrichum subpilosum P.Beauv., with numerous sunken stomata in recessed groove.

Within the class itself generic circumscriptions and relationships are now fairly confidently resolved by molecular phylogenetic analyses that are easily interpretable in terms of morphology (e.g. Bell \& Hyvönen 2010a, 2010b, 2012; Bell et al. 2015; Hyvönen et al. 1998), and, with a few notable exceptions discussed below, largely congruent with the most developed pre-molecular taxonomy (e.g. Hyvönen 1989; Smith Merrill 1996; Smith 1971). Here we provide an up-to-date summary of this phylogeny with reference to a new analysis based on representative sampling from previously published molecular data and use this as a framework for a concise review of diversity within the group.

The large majority of the Polytrichopsida are easily distinguished from other mosses even by non-bryologists. Typical features associated with the group are their large size relative to other mosses, leaves with specialized basal sheaths and laminas covered with photosynthetic lamellae, and relatively large sporophytes with rigid setae and capsules protected by hairy calyptrae. All of these features can be observed, for example, in the common hair-cap moss, Polytrichum commune Hedw., often used as an exemplary moss in botanical teaching materials. Many or all of these features are absent in some species within the group, however, and the extant species show considerable diversity in morphology, and especially size. The smallest species, with persistent protonema and very reduced gametophytes, such as Pogonatum piliferum (Dozy \& Molk.) Touw, are comparable in size to numerous other bryophytes while the gametophytes of Dawsonia R.Br. can reach $65 \mathrm{~cm}$ in height with leaves exceeding $40 \mathrm{~mm}$ in length. These are the largest self-supporting embryophyte gametophytes, functionally comparable in many respects to vascular plant sporophytes (e.g. Brodribb et al. 2020). 


\section{Materials and methods}

Based on previously published datasets (Bell \& Hyvönen 2010a, 2010b, 2012; Bell et al. 2015, 2017) we assembled a novel matrix of terminals representing diversity across the class and sampling molecular sequence data from four regions (the mitochondrial nad5 gene, the $3^{\prime}$ half of the chloroplast $r b c L$ gene, the chloroplast $r p s 4$ gene and downstream intergenic spacer, and the chloroplast $\operatorname{trnL}-\operatorname{trn} F$ region). Voucher information and GenBank accession numbers are provided in the studies cited. Sequences were manually aligned using PhyDE v.0.997 (Müller et al. 2011). For the protein coding regions ( $r b c L$, the $r p s 4$ gene, $n a d 5$ exon) there was no alignment ambiguity, while for the non-coding regions (nad5 intron, most of $\operatorname{trnL}-F$, rps 4 -trnS intergenic spacer) the majority of the alignment was unambiguous, with ambiguity mostly restricted to short mono-and dinucleotide repeats (generally of A and T), which were excluded. Also excluded was a previously identified hairpin-associated inversion in the $\operatorname{trn} L-F$ region that is variably present and known to be highly homoplastic (Quandt et al. 2004, 2007; Quandt \& Stech 2005; Bell et al. 2007). Partitions were defined for each region independently. MrModeltest v.2.2 (Nylander 2004) was used for initial estimation of the best-fitting models for each partition using the Akaike information criterion (Akaike 1974). The most complex model selected for any one partition was then applied independently to all partitions prior to analysis according to the maximum likelihood criterion using RAxML v.7.4.2. (Stamatakis 2006) with the raxmlGUI v.1.3 front end (Silvestro\& Michalak 2012). Members of the genus Polytrichastrum were constrained to form a monophyletic group for illustrative purposes, because although the genus is supported by multiple morphological synapmorphies and is never well-supported as non-monophyletic by bootstrap values, $P$. sexangulare and $P$. sphaerothecium are sometimes ambiguously resolved. The "ML + thorough bootstrap" option within the raxmlGUI (RAxML option "-b" followed by an ML search) was used on the partitioned dataset, with 20 runs and 500 replications.

\section{Results}

The GTR $+\Gamma+$ I model was selected as optimal for all compartments with the exception of the rps 4 region, for which the GTR $+\Gamma$ model was selected. Thus, the GTR $+\Gamma+$ I model was applied to all compartments independently in the RAxML analysis. The optimal tree with bootstrap values $>50 \%$ is shown in Fig. 3.

\section{Historical taxonomy and phylogeny}

Some of the hair-cap mosses were treated in $17^{\text {th }}$ C. herbals (e.g. Sutherland 1689), most likely based on much older knowledge and usage, while Polytrichum commune was among the first mosses illustrated in the era preceding Linnaeus (Dodens 1578). Hedwig (1801) included 17 species in the genus Polytrichum in his treatment of mosses, many of which were subsequently placed in separate genera to accommodate observed variation. Fleischer (1923) presented ideas about phylogeny of Polytrichopsida in his extensive work on S.E. Asian mosses, and Brotherus (1925), in his general treatment of mosses, divided the group into two families, the Dawsoniaceae and Polytrichaceae. Gary L. Smith laid the foundations for the modern taxonomy of the Polytrichopsida with numerous studies on the group, and particularly his conspectus (Smith 1971). His revised generic classification is still largely in use today although concepts of some genera, e.g. Pogonatum P.Beauv., Polytrichastrum G.L.Sm. and Polytrichum Hedw., have subsequently been modified (e.g., Bell \& Hyvönen 2010b, Hyvönen 1989, Touw 1986).

In his conspectus, Smith (1971) presented a schematic phyletic arrangement of the genera of the Polytrichaceae with a brief discussion, together with a list of phylogenetic trends, i.e., a table of characters and their assumed primitive and derived states. The PhD thesis of one of the authors (Hyvönen 1989) included a cladistic analysis of the genus Pogonatum but performed using only manual Hennigian argumentation. In this work three entities of the Polytrichopsida were assumed to comprise an unresolved basal trichotomy. The first search-based phylogenetic analysis of the group was in the MSc thesis of Forrest (1995) and based on 50 morphological characters. This was followed by an analysis by Hyvönen et al. (1998) that included, in addition to 39 morphological characters, nuclear and chloroplast gene sequences. This found Alophosia azorica (Ren. \& Card.) Card., an endemic species restricted now to Macaronesia, to represent the earliest diverging lineage in the extant Polytrichopsida (Fig. 2), a result that has been confirmed by many studies since (e.g. Bell \& Hyvönen 2008; Flores et al. 2020). Subsequent molecular phylogenetic studies with greatly increased character and taxon sampling have further resolved major clades within the class, refined the circumscription of genera and offered insights into the evolution of features such as the polytrichaceous peristome (Bell et al. 2010, 2010b, 2012; Bell et al. 2015; Hyvönen et al. 2004). 


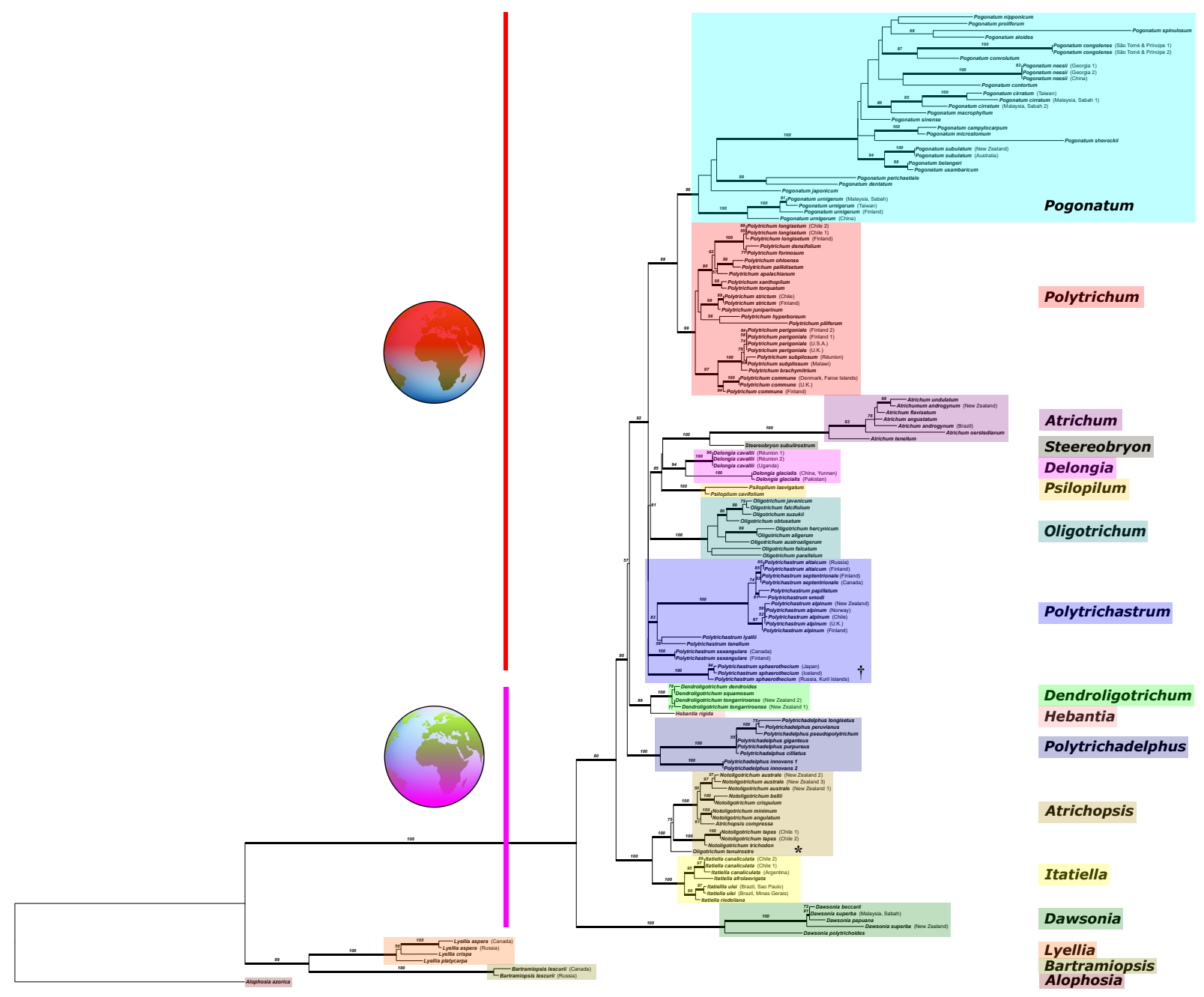

FIGURE 3. Maximally likely topology from analysis of concatenated $r b c L, r p s 4$, $\operatorname{trnL} L \mathrm{t} r n F$ and $n a d 5$ matrix assembled from sequences published in previous studies (see text). Numbers on branches are bootstrap values above $50 \%$ and branches supported at $>=80 \%$ bootstrap are represented by thickened lines. All currently recognised extant genera are included, with each genus represented by a coloured box. Shaded globe icons and corresponding coloured lines indicate genera that have their centres of extant diversity in the Southern Hemisphere (magenta) and the Northern Hemisphere (red). Where multiple exemplars of species are included, countries of origin (and in some cases also regions) are provided for each in parenthesis. Where there are multiple exemplars of the same geographic origin these are numbered, with the numbers corresponding to those used in the original publications cited. $\uparrow$ Monophyly of the genus Polytrichastrum was constrained during the analysis (see "Materials and Methods). * Species of Notoligotrichum, as well as Oligotrichum tenuirostre, will be combined under Atrichopsis elsewhere (see "Historical Taxonomy and Phylogeny").

Perhaps the most prominent and confusing taxonomic changes in the group over the last half century (due to the ubiquity of the species in northern temperate areas) have been in the genus Polytrichum as traditionally delimited. Smith (1971) found that Polytrichum is morphologically heterogenous, particularly in some fundamental, if microscopic, features of the peristome that had previously been observed by Lindberg (1868) and used as the basis of his subgenera Pterygodon and Leiodon. Smith (1971) erected the segregate genus Polytrichastrum with P. alpinum as the type, but including also many other familiar northern temperate species such as Polytrichum formosum Hedw. and P. pallidisetum Funck. Subsequent phylogenetic analyses (Bell \& Hyvönen 2010a, 2010b) have shown that Polytrichastrum is indeed rather distantly related to Polytrichum s.s., but as originally proposed was too widely circumscribed, thus a number of species were transferred back to Polytrichum by Bell \& Hyvönen (2010b).

The genus Psilopilum Brid., previously a moderately-sized genus with a bipolar distribution, was also proposed by Smith (1971) to represent a heterogenous assemblage. Smith transferred most of the southern hemisphere species into a new genus Notoligotrichum G.L.Sm. based largely on capsule characters, a decision that has been corroborated by 
subsequent molecular phylogenetic studies (Bell \& Hyvönen 2010a, 2012). Other genera that Smith (1971) suspected to be heterogenous have been further revised after phylogenetic analyses (e.g., Bell et al. 2015; Kariyawasam et al. 2018) confirmed them to be para-or polyphyletic, most notably Oligotrichum DC. (e.g. Bell \& Hyvonen 2012). These studies also showed that Atrichopsis compressa (Hook.f. \& Wilson) G.L.Sm., the sole representative of that genus first combined under Atrichopsis Cardot by Smith (1969), was derived from within Notoligotrichum, a finding that led Bell \& Hyvönen (2012) to erroneously combine it under Notoligotrichum. Naturally, Atrichopsis, as an older name, has priority and all species of Notoligotrichum are required to be combined under Atrichopsis. These changes are made in a separate paper (Van Rooy et al., submitted).

The latest generic additions to the Polytrichopsida are Delongia N.E.Bell et al. (2015), and the fossil Meantoinea Bippus \& al (2017).

\section{Extant diversity \& evolution}

The Polytrichopsida comprise 19 genera with two known only from fossils (Fig. 3). Most are numerically small, the most notable exception being Pogonatum with over 50 species. Considering current phylogenetic hypotheses in the light of morphology and global distributions it would seem that Alophosia Card., Bartramiopsis Kindb., and Lyellia R.Br. (the earliest diverging lineages according to molecular phylogenetic analyses) are relicts, with scattered and disjunct distributions in the Northern Hemisphere. The single extant species of Alophosia occurs only in the Azores and on Madeira, although the lineage it represents must have been more widespread in the past as these islands are considerably younger than the node from which it is derived (Bell and Hyvönen 2010a, Bell et al. 2015). Batramiopsis, also monotypic, has a "northern Pacific Radiant" distribution (Smith Merrill 2007) in N. W. North America, Japan and Eastern Siberia, while Lyellia has one species in North America and Siberia and two others in S. E. Asia. The feature shared by these old lineages, and also with the fossil Meantoinea, is the lack of a peristome. Instead they have a "stopper mechanism" at the capsule mouth composed of an enlarged apical section of the columella and often an expanded, flattened capsule rim (Fig. 1; see also Fig. 5A of Bell \& Hyvönen, 2010a).

All other lineages in the class have nematodontous peristomes developed from bundles of "u-shaped" cells (Smith, 1971), with the tips of the teeth attached to a variably membranous or fleshy drum-like structure called the epiphragm (Figs. 1,2), which is clearly homologous to the "stopper" found in Alophosia, Bartramiopsis and Lyellia. Thus, it appears that the polytrichaceous peristome has evolved by elongation and curvature in the innermost cells of the inner ampithecial layers to form crenellations at the margin of a primitively unornamented aperture, these then becoming bonded (to lesser or greater degrees in different genera) to the pre-existing proto-epiphragm represented by the "stopper". In the most derived genera such as Atrichum P.Beauv., Polytrichum and Pogonatum, the tips of the teeth are usually tightly bonded to the epiphragm (which is entirely detached from the lower parts of the columella when the capsule is mature), while in some species in earlier diverging groups such as Atrichopsis, the epiphragm is thicker, less expanded and less securely attached to the peristome, and the peristome teeth can much more obviously be seen as developments from the rim of a structure homologous to the flattened "disc" seen in Alophosia and Lyellia (Fig 2). This evolutionary series would presumably have accompanied a gradualist trend from relatively abrupt dehiscence via the opening of a stopper, to more controlled spore dispersal, potentially over a much longer period, mediated by the gaps between the peristome teeth and the epiphragm.

The more widespread species of the Northern Hemisphere in which these trends in peristome evolution are most developed appear to represent a younger clade separated from the earliest diverging lineages by a grade of predominantly southern hemisphere genera, within which peristomes often appear less developed, albeit variably so. The genus Dawsonia, on the other hand, which is sister to all other peristomate taxa, differs from all other members of the class in its unique peristome composed of long, bristle-like teeth arranged in concentric layers. These are tightly coiled when the operculum is shed and subsequently "unwind" to form an irregular tuft of bristles through which spores are gradually released, in a manner analogous to the specialist type of haplolepidous perstome found in some Pottiaceae. This presumably represents a parallel evolutionary development from the earliest type of proto-peristome found in the common ancestor of all peristomate Polytrichopsida. It was because of this feature that Brotherus (1925) placed the genus in its own family. However, based on the results of recent phylogenetic analyses this would necessitate the recognition of at least two additional families to accommodate older lineages. While this would certainly be possible we do not believe it would be useful at this time, particularly as numerous new fossils await formal description (see below) that have the potential to clarify evolutionary trends connecting Alophosia, Bartramiopsis and Lyellia. Dawsonia was revised by Zanten (1973) based on comprehensive sampling of all species, although a modern analysis 
of this small genus incorporating molecular characters would be informative and could be an ideal topic for an MSc thesis project. The species are found exclusively in Australasia and S. E. Asia, usually in forest environments, and as mentioned above represent the largest extant self-supporting mosses. They have one of the best developed vasculature systems found in bryophtytes, with hydroids and leptoids present in leaf traces that extend continuously from the stem central strand to the leaf nerve (Goebel 1906). This might be expected to be at least as efficient as the vascular system of Polytrichum commune, recently shown to be functionally comparable to that of tracheophytes (Brodribb et al. 2020).

Many species of the traditional heterogenous genera found to be polyphyletic in recent molecular phylogenetic studies (Bell \& Hyvönen 2010b, 2012) are part of a southern hemisphere grade found already by Hyvönen et al. (1998) and are only distantly related to the superficially similar northern hemisphere species with which they were historically classified. Most species in this grade have fairly limited extant distributions and are usually of small stature, the exceptions being those placed in Dendroligotrichum (Mull.Hal.) Broth. and Polytrichadelphus (Muill. Hal.) Mitt., some of which are comparable in the size to Dawsonia and the larger species of the Northern Hemisphere. Dendroligotrichum is a small genus of only three species found in Patagonia and New Zealand, easily identified by its dendroid habit. Species of Polytrichadelphus are also found on both sides of the Pacific but the range of the genus is considerably wider, both in Australasia and South America, with the largest number of species occurring in the Andes. A comprehensive global revision of this genus is still lacking, although the species occurring in Colombia were recently revised by Aponte \& Uribe (2017). The gametophytes of Polytrichadelphus closely resemble those of Polytrichum and Polytrichastrum, although the capsules are biconvex or more or less asymmetrically 3-4 angled rather than being symmetrically round or 4-6 angled, the calyptrae not conspicuously hairy, and the peristomes similar to those of other southern hemisphere genera, with small, slightly irregular, gradually narrowed teeth that are often orientated more horizontally than vertically. Interestingly, in both Polytrichadelphus and Dendroligotrichum, the sole Australasian representatives, P. innovans (Müll.Hal.) A.Jaeger and D. tongariroense (Colenso) Tangney, were until recently usually treated as conspecific with their close relatives in Patagonia, P. magellanicus (Hedw.) Mitt. and $D$. dendroides (Brid. ex Hedw.) Broth., although molecular analyses have now shown them to be distinct. All of the genera in this southern hemisphere grade of Polytrichopsida clearly have their origins in the Cretaceous fragments of Gondwana and many (e.g. Dendroligotrichum) still have their extant distributions limited to temperate Australasia and Patagonia. Polytrichadelphus has presumably undergone a more recent radiation in tropical America from temperate ancestors, as evidenced by the long stem branch separating the relatively speciose tropical clade from its isolated temperate relatives (Fig. 3).

The remaining eight genera in the class comprise a large apical clade that accounts for at least $75 \%$ of all species. In contrast to the genera in the southern hemisphere grade, all are most speciose in northern temperate regions or the Asian tropics. Many species are both widespread and common, particularly in fairly young post-glacial environments. In some habitats of the boreal zone, for example mires with closed canopies dominated by conifers (mostly species of Picea A. Dietr.), Polytrichum commune can be a dominant plant of the ground layer. In general, however, species of Polytrichopsida thrive in fairly open, recently disturbed habitats. Some species can even be characterized as weeds and obviously benefit from human activity that creates new open habitats.

Polytrichastrum remains a fairly heterogenous group even after the return of the species placed by Smith (1971) in section Aporotheca to Polytrichum by Bell \& Hyvönen (2010b). It is distinguished from Polytrichum by capsules that are either terete or multiple-angled (4-6 angled, but not consistently and symmetrically 4-angled), and the presence of elongated "epiphragm teeth" in all but one species (Bell \& Hyvönen 2010b). A core group of species typified by $P$. alpinum have entirely terete capsules. Polytrichastrum alpinum itself has a widespread bipolar distribution, and while sequences of some markers from areas as far apart as New Zealand and the Arctic are identical suggesting a very close relationship, Biersma et al. (2017) found population structure in the nuclear ITS region suggestive of the origins of the Antarctic populations by dispersal from the Holarctic region. Other species closely related to P. alpinum have more restricted distributions in the Himalayas and in northern boreal and arctic regions and can sometimes be difficult to tell apart from forms of $P$. alpinum occurring in the same habitats, such is the plasticity of form in P. alpinum, although molecular markers clearly distinguish them (Fig. 2, Bell \& Hyvönen 2010b). The other species falling outside of this core group generally have multiple-angled capsules (almost certainly a plesiomorphic condition), while their placement in a monophyletic Polytrichastrum is less confident (Fig. 3). Polytrichastrum sexangulare (Flörke ex Brid.) G.L.Sm. and P. sphaerothecium (Besch.) J.-P.Frahm in particular are often poorly resolved phylogenetically in relation to the other species in the genus and occasionally appear in sister group relationships with other clades (e.g. Oligotrichum or Polytrichum / Pogonatum), although never with even moderate support values. In our current phylogeny (Fig. 3) the monophyly of Polytrichastrum has been constrained, although it remains possible that these two species represent one 
or two undescribed distinct genera. Intriguingly, Derda \& Wyatt (2000) presented evidence that $P$. sexangulare is an allopolyploid with the much less widespread $P$. sphaerothecium as one of its progenitors.

Oligotrichum as now circumscribed is a genus of around 12 species with a center of diversity in the Sino-Himalaya (Kariyawasam et al. 2018). Other species are found throughout the boreal and arctic regions and a single species, $O$. austroaligerum G.L.Sm., is endemic to southern temperate areas (in S. America). Other southern hemisphere species previously placed in the genus are now classified in Itatiella or in some cases Notoligotrichum / Atrichopsis (Bell \& Hyvönen 2012). Plants are nearly all small with ventral lamellae mostly restricted to the nerve, although many species also have dorsal lamellae, an unusual feature in the Polytrichopsida. Similar to Oligotrichum, Psilopilum traditionally included a number of southern hemisphere species (mostly temperate) before these were moved to Notoligotrichum by Smith (1971). It now comprises only two rather similar species occurring on disturbed soils in the arctic.

Delongia was described recently (Bell et al. 2015) to accommodate two montane species previously placed in Oligotrichum, these being notably disjunct between East Africa (in the Rift Mountains and on the island of Réunion) and the Himalaya. More closely related to Psilopilum and Atrichum than to Oligotrichum, Bell et al. (2015) hypothesised a shared common ancestor with one of those genera (together with Steereobryon G.L.Sm. in the case of Atrichum) in the Eocene based on dating analyses. Although rather morphologically divergent, the two species are united by aspects of capsule morphology, particularly the "spongy" tissue of the apophysis that to some extent obscures the stomata when dry.

In terms of species diversity, the three largest genera in the large predominantly Holarctic clade are Atrichum, Pogonatum and Polytrichum. The former was revised by Nyholm (1971), while Pogonatum was treated by Hyvönen (1989) and revisionary studies of Polytrichum sect. Polytrichum are currently in preparation by Kariyawasam et al. While these three genera are predominantly distributed in the Northern Hemisphere all of them also have some species exclusively found in the southern continents. Despite the fact that both Atrichum and Pogonatum were relatively recently revised, it is clear that both offer numerous opportunities for more detailed studies. Recent work (Perley \& Jesson 2015) has shown that hybridization has occurred repeatedly in Atrichum, complicating the resolution of its phylogeny and taxonomy. Our own analyses (Bell \& Hyvönen 2008, 2010a), which include sampling of both nuclear and chloroplast genes, hint at possible ancient hybridization also in some species of Pogonatum. While taxonomic treatment of this genus is more recent it is clear that there are numerous taxa still in need of more thorough study. The largest number of species can be found in S. E. Asia and in the northern parts of South America and it is in these regions that more detailed work is required. This could easily lead to the discovery of new species, even in areas that are fairly well known bryologically, as exemplified by the recent description of $P$. shevockii from Taiwan and Yunnan (Bell et al. 2017). Already it is clear based on our later analyses (e.g. Bell et al. 2017; Koskinen \& Hyvönen 2004) that most of the subgenera proposed in Hyvönen (1989) do not represent natural groups. The most striking phylogenetic pattern in the genus (Fig. 3 ) is the separation of an apical clade containing most species from a small group of early diverging taxa (P. urnigerum, $P$. dentatum, $P$. japonicum and $P$. perichatiale) by a notably long branch, hinting at increased rates of evolution associated with the diversification of this speciose group. The genus Atrichum is separated from its sister genus Steereobryon by a similarly long branch (Fig. 3). Interestingly, both of these derived and geographically widespread groups are characterized by capsules in which stomata have been lost and peristome teeth are very robust. Over the decades we have gradually accumulated more sequence level data of numerous species of Pogonatum and a comprehensive phylogenetic analysis of this genus is in preparation.

\section{Anatomy and physiology}

While bryophytes generally are poikilohydric, ectohydric and adapted to boundary layer microhabitats favouring small plant size, many of the Polytrichopsida are relatively larger plants with well-developed vasculature and a "pseudomesophyll" capable of supporting relatively high rates of photosynthesis in moist, well-illuminated environments (Proctor, 2005; Smith, 1971; Wang et al. 2017). This lifestyle seems to have arisen very early in the evolution of the group, as it is present to varying degrees in Lyellia, Bartramiopis and especially Dawsonia. It is retained in youngeroriginating genera such as Dendroligotrichum, Polytrichadelphus and Polytrichum, although secondarily lost to some degree in several other lineages independently (Bell \& Hyvönen 2010a, 2012; Smith 1971).

Marschall \& Proctor (2004) and Proctor (2005) showed that in contrast to other mosses, many species of Polytrichopsida with well-developed lamellae show high levels of light saturation for photosynthesis, "approaching or even exceeding full midday sunlight, and comparable with vascular 'sun plants'". Furthermore, chlorophyll 
fluorescence measurements show light responses contrasting with those of full-sun exposed mosses with unistratose leaves, in which photosynthetic electron flow was limited at higher irradiance levels. This is likely because the lamellae of Polytrichopsida act to greatly increase the surface area for $\mathrm{CO}_{2}$ uptake, which is limiting for photosynthesis in environments where irradiance and water are in ample supply such as the open mire habitats where Polytrichum commune grows most abundantly (Proctor 2005). Wang et al. (2017) similarly showed that Polytrichopsida species were distinct from other mosses with regard to their photosynthetic capacities, chlorophyll concentrations and light requirements.

Linked to this ability to support high photosynthetic rates enabled by the increased $\mathrm{CO}_{2}$ uptake capacity of the lamellae is the ability of the developed vascular system (the hydrome and leptome) to efficiently distribute resources (particularly water) within the plant (Atala \& Alfaro 2012; Wang et al. 2017). Recently it was shown that the hydroidbased vascular system in Polytrichum, which (unlike in any non-Polytrichaceous moss that has been studied) has long been known to be fully continuous from the stem to the leaves (Goebel 1906), is also functionally capable of efficient water transport. Brodribb et al. (2020) demonstrated that Polytrichum hydroids are able to resist the buckling forces associated with the negative water potentials necessary in vascular plants to extract water from the soil through transpiration, a capability previously thought to be restricted to the lignified vasculature of tracheophytes. Furthermore, the water transport efficiency of the Polytrichum vascular system and resistance to cavitation were compatible with maintaining the continuous water column necessary to support photosynthesis in an endohydric plant. Finally, Polytrichum commune is apparently able to regulate gas exchange in response to atmospheric conditions (i.e. to regulate transpiration rates to balance photosynthetic rates against desiccation), an ability that may be linked to lamellar end cells closing off the inter-lamellar spaces when dry, and leaf orientation changing dramatically (Brodribb et al. 2020). Critically however, this study also showed that despite the suspected ability of lamellae to increase total $\mathrm{CO}_{2}$ diffusion rates, Polytrichum has a much less efficient exchange ratio of water for photosynthetic $\mathrm{CO}_{2}$ than comparable tracheophytes, likely linked to a comparatively high cellular resistance to $\mathrm{CO}_{2}$ diffusion in its leaves. Thus, it requires moist air to support high rates of photosynthesis.

Relating the above findings to the diversity of ecology and morphology in the Polytrichopsida, it would appear that some species may have the potential to compete with tracheophytes on their own terms as large endohydric plants, but perhaps only in very humid environments where the availability of atmospheric moisture at significant distances above ground is not restricting. This fits with the range of habitats in which very large Polytrichaceae occur-humid tropical cloud forests (Dawsonia, some large species of Pogonatum such as P. cirratum ssp. macrophyllum (Dozy \& Molk.) Hyvönen, the derived Andean clade of Polytrichadelphus), cool temperate rain forests (Dendroligotrichum dendroides, Polytrichum formosum etc.), and very wet open habitats such as mires in oceanic temperate areas (Polytrichum commune etc.). Other species in the class are presumably secondarily adapted to dryer habitats through a compromise between this lifestyle and a more typical bryophytic ectohydric existence in the boundary layer.

\section{Fossil record}

With ten described species, Cenozoic fossils of Polytrichopsida (or species tentatively assigned to the group) are fairly numerous compared with other mosses (Frahm 2004, Bippus et al. 2017). Records of fossils from older sediments have, however, been rare. Before description of the exquisitely preserved Eopolytrichum antiquum Konopka et al. (1997) from the Upper Cretaceous sediments of Georgia, USA, the only fossil tentatively assigned to Polytrichopsida was the Carboniferous Muscites polytrichaceus (Renault \& Zeiller, 1888). However, the details of this fossil are unfortunately so poorly preserved that its affinity with Polytrichopsida is equivocal at best, and most likely erroneous (Ignatov \& Shcherbakov 2009). Recently several well-preserved fossils of Polytrichopsida have been found in the Early Cretaceous sediments of Vancouver Island in British Columbia, Canada, and one new species, Meantoinea alophosioides Bippus et al. (2017), has already been described. Both of the well-preserved and accurately described North American fossils have been included in phylogenetic analyses together with extant taxa (Bippus et al. 2018, Flores et al. 2020; Hyvönen et al. 1998). Besides these two fossils, Heinrichsiella patagonica Bippus et al. (2019) was recently described from the Patagonian (Santa Cruz, Argentina) Late Jurassic (ca. $150 \mathrm{Ma}$ BP) cherts. Its taxonomic affinity was described as being either with the Polytrichopsida or the Timmiellaceae. Additionally, there are at least seven other specimens of Polytrichopsida from Cretaceous sediments in various parts of the world (Vancouver Island, New Jersey, Portugal) that still await detailed description (Bippus, pers. comm.). Incorporating all these findings into phylogenetic analyses promises to be highly informative for understanding the evolution of the group as well as for more accurately calibrating dating studies. 


\section{Future work}

Polytrichum commune is frequently used as a "model" plant in diverse fields of biology, probably due to its large size and ubiquity in Europe and North America (although many plants identified as P. commune in North America may in fact be P. perigoniale Michx.; Kariyawasam, in prep.). For bryophytes, citations of Polytrichum are exceeded only by Marchantia L., Physcomitrella Bruch \& Schimp. and Sphagnum L. Nonetheless, despite being described in Hedwig's Species Muscorum, Polytrichum commune was only formally typified this year (Kariyawasam et al. 2021).

As detailed above, Polytrichopsidan genera such as Polytrichum and Dawsonia represent the current end point of an atypical evolutionary trend in mosses towards vascularization, endohydry and relatively large plant size. Because $P$. commune is easily collected in northern temperate regions it is the ideal subject for comparative studies into vascular endohydry in bryophytes and tracheophytes and the extent to which these are homologous. The highly developed conducting tissue of $P$. commune has been studied extensively in the past (summarized in Ligrone et al. 2012), and its function is only now beginning to be understood (Brodribb et al. 2020).

The Polytrichopsida would also be an ideal group in which to further study the role of stomata in moss sporophytes and the variation in the expression of these, as recently thoroughly studied by Renzaglia et al. (2020). Their conclusion, based on sampling across mosses, was that stomata have been independently lost over 60 times, while moss capsules have a complex anatomy of internal spaces associated with stomata and with sporangial development and nourishment, despite stomata themselves not being fundamentally necessary for these processes. Variation in presence, number and associated morphologies of stomata is highly evident in the Polytrichopsida. While in two of the most derived lineages, Pogonatum and Atrichum, stomata are entirely absent, other lineages such as Polytrichum and Delongia have stomata associated with additional external structures in the apophysis as well as with internal spaces (Fig. 2). Meanwhile, the role of stomata in tracheophytes is apparently performed by other structures entirely in the Polytrichopsida (see above). The likely analogous role of lamellar end cells in modulating transpiration and water loss from the inter-lamellar spaces of "pseudo-mesophyll" would be a fascinating focus for physiological, developmental and comparative genomic studies.

Considering all these potential topics, obtaining high-quality annotated genomes for selected species of Polytrichopsida would be highly desirable. Towards this end we have submitted a proposal for in-depth sequencing and annotation of the Polytrichum commune genome. Both chloroplast and mitochondrial genome sequences already exist, with the latter recently published (Goryunov et al. 2021). A transcriptome of the genome has also been obtained, though not yet released within the large Chinese led 1KP consortium (https://db.cngb.org/onekp/). Nonetheless, if our proposal is not successful this species, along with Atrichum undulatum (Hedw.) P.Beauv., has already been selected to be sequenced within the first phase of the large Darwin Tree of Life project (DToL, darwintreeoflife.org) devoted to the biota of the British Isles.

As mentioned above there remains a need for basic taxonomic work in some groups of the Polytrichopsida. There are still genera that have not been properly revised, and even in some that have there are species that deserve more detailed scrutiny, especially those with large ranges in regions with complicated geological histories. While new collections might lead to description of new species (e.g. Pogonatum shevockii, Bell et al. 2017), existing herbarium collections are also likely to contain misidentified specimens representing undescribed species (as with P. norrisii, Hyvönen, 1989). The same applies, perhaps even more so, to the fossil record of the Polytrichopsida, and mosses in general. Due to their small size moss fossils have likely been overlooked in the past and thus re-examination of specimens already in collections might reveal new valuable material. Further, more detailed studies of some taxa with very wide ranges are likely to be facilitated by the rapid development and reduced cost of various techniques enabling the use of high-throughput sequence level data to study taxonomy, making it feasible to process large numbers of specimens covering all parts of a species' range.

For an organismal group with less than 300 species, obtaining a robust phylogenetic hypothesis based on comprehensive sampling and analysis of whole genomes cannot be considered an unrealistic goal in the coming years. Revisions of larger genera could be achieved through $\mathrm{PhD}$ projects focusing on taxonomy in conjunction with wider evolutionary questions. Meanwhile regional revisions (e.g. Allen 2018; De Sloover 1986; Hyvönen 2006; Long 1985; Peralta \& Yano 2010; Smith Merrill 1993) including studies of type material continue to incrementally improve our understanding of this group.

While whole genomes might appear to be a Rosetta Stone for phylogeny it is equally important to remember that even massive amounts of data can be misleading if not analyzed properly. While superficially it might appear that there is now a widely accepted consensus on appropriate analytical methods, fundamental theoretical questions still need 
to be debated. Aspects such as forms of statistical likelihood used as an optimality criteria in model-based analyses, how sequence alignment is performed, modelling of compositional heterogeneity and substitutional saturation of synonymous sites in protein coding regions (e.g., De Sousa et al. 2018) all have the potential to greatly affect results. Equally important is the incorporation of fossils in analyses as recently pointed out for example by Lehtonen et al. (2020) and Flores et al. (2021), showing how even poorly known fossils can enhance the accuracy of phylogenetic analyses.

While the future of basic taxonomic work sometimes appears bleak given contemporary funding priorities, we should not take a pessimistic view of the future of bryophyte taxonomy, and perhaps keep in mind the example of Viktor Ferninand Brotherus, Altmeister der Bryologie, who can still be considered the greatest moss taxonomist of all time. He never had a position in the university but worked as a high school teacher (Koponen \& Piippo 2002), obtaining his great results as an amateur, in the verbatim meaning of this term.

\section{Acknowledgements}

We thank numerous colleagues (too many to list) for their kind assistance through correspondence, during visits to herbaria, and on field-work, and for sending specimens on loan. Our studies would not have been possible without this support. Equally important has been the funding received, almost exclusively, from public resources. We are forever in debt to our fellow taxpayers for supporting essential research infrastructure and basic studies of biological diversity. The Royal Botanic Garden Edinburgh (RBGE) is supported by the Scottish Government's Rural and Environment Science and Analytical Services Division. During 2020 we are also grateful for the support of players of People's Postcode Lottery towards our scientific research.

\section{References}

Akaike, H. (1974) A new look at the statistical model identification. IEEE Trans. Automatic Control 19: 716-723. https://doi.org/10.1109/TAC.1974.1100705

Allen, B. (2018) Moss flora of Central America. Part 4. Fabroniaceae-Polytrichaceae. Missouri Botanical Garden Press, 840 pp.

Aponte, R.A. \& Uribe, M.J. (2017) Revisión de la familia Polytrichaceae (Bryophyta) para Colombia. Boletín de la Sociedad Argentina de Botánica 52: 209-250.

https://doi.org/10.31055/1851.2372.v52.n2.17438

Atala, C. \& Alfaro, J.F. (2012) Vascular architecture of the dendroid antipodean moss Dendroligotrichum dendroides (Brid. ex Hedw.) Broth. (Polytrichaceae). Journal of Bryology 34: 277-280. https://doi.org/10.1179/1743282012Y.0000000032

Bell, N.E. \& Hyvönen, J. (2008) Rooting the Polytrichopsida: the phylogenetic position of Atrichopsis and the independent origin of the polytrichopsid peristome. In: Mohamed, H. (Ed.) Bryology in the new millennium. University of Malaya, Kuala Lumpur, pp. $227-239$.

Bell, N.E. \& Hyvönen, J. (2010a) Phylogeny of the moss class Polytrichopsida (Bryophyta): generic level structure and incongruent gene trees. Molecular Phylogenetics \& Evolution 55: 381-398.

https://doi.org/10.1016/j.ympev.2010.02.004

Bell, N.E. \& Hyvönen, J. (2010b) A phylogenetic circumscription of Polytrichastrum (Polytrichaceae): Reassessment of sporophyte morphology supports molecular phylogeny. American Journal of Botany 97: 566-578. https://doi.org/10.3732/ajb.0900161

Bell, N.E. \& Hyvönen, J. (2012) Gametophytic simplicity in Laurasian and Gondwanan Polytrichopsida-The phylogeny and taxonomy of the Oligotrichum morphology. Journal of Bryology 34: 160-172. https://doi.org/10.1179/1743282012Y.0000000015

Bell, N.E., Kariyawasam, I.U., Hedderson, T.A.J. \& Hyvönen, J. (2015) Delongia gen. nov., a new genus of Polytrichaceae (Bryophyta) with two disjunct species in East Africa and the Himalaya. Taxon 64: 893-910. https://doi.org/10.12705/645.2

Bell, N.E., Hyvönen, J., Yao, K.-Y. \& Ma, W.-Z. (2017) Description and phylogenetic investigation of Pogonatum shevockii N.E.Bell \& Hyvönen (Polytrichaceae), a new East Asian species with a unique leaf morphology. Journal of Bryology 39 (3): $235-246$. 
https://doi.org/10.1080/03736687.2017.1312732

Bell, N.E., Quandt, D., O’Brien, T.J. \& Newton, A.E. (2007) Taxonomy and phylogeny in the earliest diverging pleurocarps: Square holes and bifurcating pegs. Bryologist 110: 533-560. https://doi.org/10.1639/0007-2745(2007)110[533:TAPITE]2.0.CO;2

Biersma, E., Jackson, J., Hyvönen, J., Koskinen, S., Linse, K., Griffiths, H. \& Convey, P. (2017) Global biogeographic patterns in bipolar moss species. Royal Society Open Science, 4 (7): 170147. https://doi.org/10.1098/rsos.170147

Bippus, A.C., Stockey, R.A., Rothwell, G.W. \& Tomescu, A.M.F. (2017) Extending the fossil record of Polytrichaceae: Early Cretaceous Meantoinea alophosioides gen. et sp. nov., permineralized gametophytes with gemma cups from Vancouver Island. American Journal of Botany 104: 584-597.

https://doi.org/10.3732/ajb.1700002

Bippus, A., Escapa, I.E. \& Tomescu, A.M.F. (2018) Wanted dead or alive (probably dead): stem group Polytrichaceae. American Journal Botany 105: 1-21. https://doi.org/10.1002/ajb2.1096

Bippus, A.C., Savoretti, A., Escapa, I.H., Garcia-Massini, H. \& Guido, D. (2019) Heinrichsiella patagonica gen. et sp. nov.: A permineralized acrocarpous moss from the Jurassic of Patagonia. International Journal of Plant Sciences 180: 882-891. https://doi.org/10.1086/704832

Brodribb, T., Carriquí, M., Delzon, S., McAdam, S. \& Holbrook, N. (2020) Advanced vascular function discovered in a widespread moss. Nature Plants 6: 273-279. https://doi.org/10.1038/s41477-020-0602-x

Brotherus, V.F. (1925) Musci (Laubmoose) 2. Hälfte. In: Engler, A. \& Prantl, K. (Eds.) Die natürlichen Pflanzenfamilien. 2. Aufl. 11. Engelmann, Leipzig, 542 pp.

Derda, G.S. \& Wyatt, R. (2000) Isozyme evidence regarding the origins of three allopolyploid species of Polytrichastrum (Polytrichaceae, Bryophyta). Plant Systematics \& Evolution 220: 37-53.

https://doi.org/10.1007/BF00985369

De Sloover, J.L. (1986) Note de bryologie africaine XIII.-Polytrichaceae. Bulletin du Jardin botanique National de Belgique 56: 241300. https://doi.org/10.2307/3668193

De Sousa, F., Foster, P.G., Donoghue, P.C.J., Schneider, H. \& Cox, C.J. (2018) Nuclear protein phylogenies support the monophyly of the three bryophyte groups (Bryophyta Schimp.). New Phytologist 222: 565-575.

https://doi.org/10.1111/nph.15587

Dodens, R. (1576) A Niewe Herball Translated by Henry Lyte. Gerard Dewes, London.

Fleischer, M. (1923) Die Musci der Flora Buitenzorg (zugleich Laubmoosflora von Java). Flora de Buitenzorg V: 4.

Flores, J.R., Bippus, A.C., Suárez, G.M. \& Hyvönen, J. (2021) Defying death: incorporating fossils into the phylogeny of the complex thalloid liverworts (Marchantiidae, Marchantiophyta) confirms high order clades but reveals discrepancies in family-level relationships. Cladistics [Online] https://doi.org/10.1111/cla.12442

Flores, J.R., Bippus, A.C., Tomescu, A., Bell, N. \& Hyvönen, J. (2020) Rooting morphologically divergent taxa-slow-evolving sequence data might help. bioRxiv: 2020.03.15.983684. https://doi.org/10.1101/2020.03.15.983684

Forrest, L.L. (1995) A phylogenetic analysis of Polytrichaceae (Musci). M.Sc. thesis, Dept. Botany, Univ. Reading.

Frahm, J.-P. (2004) The genus Atrichum in Baltic amber. Journal of the Hattori Botanical Laboratory 95: 219-227.

Goebel, K. (1906) Archegoniatenstudien X. Flora 96: 1-202. https://doi.org/10.1016/S0367-1615(17)32719-2

Goryunov, D.V., Sotnikova, E.A., Goryunova, S.V., Kuznetsova,O.I., Logacheva, M.D., Milyutina, I.A., Fedorova, A.V., Fedosov, V.E. \& Troitsky, A.V. (2021) The mitochondrial genome of nematodontous moss Polytrichum commune and analysis of intergenic repeats distribution among Bryophyta. Diversity 13 (2): 54.

https://doi.org/10.3390/d13020054

Hedwig, J. (1801) Species muscorum frondosorum. J. A. Barthii, Lipsiae Leipzig.

Huttunen, S, Bell, N.E. \& Hedenäs, L. (2018) The evolutionary diversity of mosses-taxonomic heterogeneity and its ecological drivers. Critical Reviews in Plant Sciences 37 (2-3): 128-174. https://doi.org/10.1080/07352689.2018.1482434

Hyvönen, J. (1989) A synopsis of genus Pogonatum (Polytrichaceae, Musci). Acta Botanica Fennica 138: 1-87.

Hyvönen, J. (2006) Genera Atrichum, Notoligotrichum, Pogonatum, Polytrichastrum, Polytrichum and Polytrichadelphus (Polytrichaceae). 
Flora of Australia 51: 124-127, 132-143.

Hyvönen, J., Hedderson, T.A., Smith Merrill, G.L., Gibbings, J.G. \& Koskinen, S. (1998) On phylogeny of the Polytrichales. Bryologist 101: 489-504.

https://doi.org/10.2307/3244524

Hyvönen, J., Koskinen, S., Smith Merrill, G.L., Hedderson, T.A. \& Stenroos, S. (2004) Phylogeny of the Polytrichales (Bryophyta) based on simultaneous analysis of molecular and morphological data. Molecular Phylogenetics \& Evolution 31: 915-928. https://doi.org/10.1016/j.ympev.2003.11.003

Ignatov, M.S. \& Shcherbakov, D.E. (2009) A new fossil moss from the Lower Permian of the Russian Far East. Arctoa 18: $201-212$. https://doi.org/10.15298/arctoa.18.14

Kariyawasam, I.U. \& Long, D.G. \& Bell, N.E. (2018) A taxonomic revision of Oligotrichum Lam. \& DC. (Polytrichaceae) in the SinoHimalaya. Journal of Bryology 40: 223-243. https://doi.org/10.1080/03736687.2018.1478651

Kariyawasam, I., Price, M.J., Bell, N.E., Long, D.G., Mill, R.R. \& Hyvönen, J. (2021) Unearthing a lectotype for Polytrichum commune Hedw. (Bryophyta, Polytrichaceae). Taxon. [Published Online] https://doi.org/10.1002/tax.12444

Konopka, A.S., Herendeen, P.S., Smith Merrill, G.L. \& Crane, P.R. (1997) Sporophytes and gametophytes of Polytrichaceae from the Campanian (Late Cretaceous) of Georgia, USA. International Journal of Plant Sciences 158: 489-499. https://doi.org/10.1086/297459

Koponen, T. \& Piippo, S. (2002) Viktor Ferninand Brotherus and his collection of letters. Bryobrotherella 5: 1-29.

Koskinen, S. \& Hyvönen, J. (2004) Pogonatum (Polytrichales, Bryophyta) revisited. Molecular systematics of bryophytes. Monographs in systematic botany from the Missouri Botanical Garden 98: 255-69.

Lehtonen, S., Poczai, P., Sablok, G., Hyvönen, J., Kargerr, D.N. \& Flores, J. (2020) Exploring the phylogeny of the marattialean ferns. Cladistics 36: 569-593.

https://doi.org/10.1111/cla.12419

Ligrone, R., Duckett, J.G. \& Renzaglia, K.S. (2012) Major transitions in the evolution of early land plants: a bryological perspective. Annals of Botany 109: 851-871. https://doi.org/10.1093/aob/mcs017

Lindberg, S.O. (1868) Observationes de formis praesertim europaeis Polytrichoidearum (Bryacearum nematodontearum). Notiser ur Sällskapets pro Fauna et Flora Fennica förhandlingar 9: 91-158.

Liu Y, Johnson, M.G., Cox, C.J., Medina, R., Devos, N., Vanderpoorten, A., Hedenäs, L., Bell, N.E., Shevock, J.R., Aguero, B., Quandt, D., Wickett, N.J., Shaw, A.J. \& Goffinet, B. (2019) Resolution of the ordinal phylogeny of mosses using targeted exons from organellar and nuclear genomes. Nature Communications 10 (1): 1485. https://doi.org/10.1038/s41467-019-09454-w

Long, D.G. (1985) Polytrichaceae. Illustrated moss flora of Arctic North America and Greenland. 1. Meddelelser om Greenland, Bioscience 17: $1-57$.

Marschall, M. \& Proctor, M.C.F. (2004) Are bryophytes shade plants? Photosynthetic light responses, and proportions of chlorophyll a, chlorophyll b and total carotenoids. Annals of Botany 94: 593-603.

https://doi.org/10.1093/aob/mch178

Müller, J., Müller, K.F., Neihuis, C. \& Quandt, D. (2011) PhyDE: Phylogenetic data editor, version 0.997. [http://phyde.de]

Nyholm, E. (1971) Studies in the genus Atrichum P. Beauv. A short survey of the genus and the species. Lindbergia 1: 1-33.

Nylander, J.A.A. (2004) MrModeltest, version 2.2. [http://abc.se/ nylander/]

Peralta, D.F. \& Yano, O. (2010) Taxonomic treatment of the Polytrichaceae from Brazil. Bryologist 113: 646-672. https://doi.org/10.1639/0007-2745-113.3.646

Perley, D.S. \& Jesson, L.K. (2015) Hybridization is associated with changes in sexual system in the bryophyte genus Atrichum. American Journal of Botany 102: 555-565. https://doi.org/10.3732/ajb.1400494

Proctor, M.C.F. (2005) Why do Polytrichaceae have lamellae? Journal of Bryology 27: 221-229. https://doi.org/10.1179/174328205X69968

Quandt, D., Müller, K., Stech, M., Hilu, K.W., Frey, W., Frahm, J.-P. \& Borsch, T. (2004) Molecular evolution of the chloroplast trnL-F region in land plants. Monographs in Systematic Botany from the Missouri Botanical Garden 98: 13-37.

Quandt, D., Bell, N.E. \& Stech, M. (2007) Unravelling the knot: The Pulchrinodaceae fam. nov. (Bryales). Beihefte Nova Hedwigia 131: 21-39.

Quandt, D. \& Stech, M. (2005) Molecular evolution of the trnL(UAA) intron in bryophytes. Molecular Phylogenetics \& Evolution 36: 429-443. 
https://doi.org/10.1016/j.ympev.2005.03.014

Renault, B. \& Zeiller, R. (1888) Flore fossile de Commentry. Bulletin Soc. Industr. Min. 3e serie, tom. ii; Études sur le Terr. Houill. d. Commentry, Livre 2: 34.

Renzaglia, K., Browning, W.B. \& Merced, A. (2020) With over 60 independent losses, stomata are expendable in mosses. Frontiers in plant science 11: 567. https://doi.org/10.3389/fpls.2020.00567

Silvestro, D. \& Michalak, I. (2012) raxmlGUI: A graphical front-end for RAxML. Organisms Diversity Evolution 12: 335 -337. https://doi.org/10.1007/s13127-011-0056-0

Smith, G.L. (1969) On Atrichopsis, with notes on some austral Psilopilum species. Bulletin of the Torrey Botanical Club 96: 60-69. https://doi.org/10.2307/2484008

Smith, G.L. (1971) A conspectus of the genera Polytrichaceae. Memoirs of the New York Botanical Garden 21: 1-83.

Smith Merrill, G.L. (1993) Polytrichaceae. In: Sharp, A.J., Crum, H. \& Eckel, P.M. (Eds.) Moss flora of Mexico, 69. Memoirs of the New York Botanical Garden, pp. i-xvii+1-1113.

Smith Merrill, G.L. (1996) Hebantia, a new genus of Polytrichaceae (Bryophyta). Journal of the Hattori Botanical Laboratory 80: $247-250$.

Smith Merrill, G.L. (2007) Polytrichaceae. In: Flora of North America Editorial Committee (Org.) Flora of North America North of Mexico, Vol. 27. Bryophytes: Mosses, Part 1. Oxford University Press, New York, pp. 121-161.

Stamatakis, A. (2006) RAxML-VI-HPC: Maximum likelihood-based phylogenetic analyses with thousands of taxa and mixed models. Bioinformatics 22: 2688-2690.

https://doi.org/10.1093/bioinformatics/bt1446

Sutherland, J. (1689) Hortus Medicus Edinburgensis: or A Catalogue of the Plants in the Physical Garden at Edinburgh. Edinburgh: Heir of Andrew Anderson.

Touw, A. (1986) A revision of Pogonatum sect. Racelopus, sect, nov., including Racelopus Dozy \& Molk., Pseudoracelopus Broth, and Racelopodopsis Thér. Journal of the Hattori Botanical Laboratory 60: 1-33.

Wang, Z., Bader, M.Y., Liu, X., Zhu, Z.M. \& Bao, W.K. (2017) Comparisons of photosynthesis-related traits of 27 abundant or subordinate bryophyte species in a subalpine old-growth fir forest. Ecology \& Evolution 7: 7454-7461.

https://doi.org/10.1002/ece3.3277

Zanten, B.O. van (1973) A taxonomic revision of the genus Dawsonia R. Brown. Lindbergia 2: 1-48. 